\title{
Exploring the Role of Mindfulness as a Potential Self-Management Strategy for Physiotherapy Students when on Clinical Placement
}

\author{
Di Thomson \\ Kingston University and St George's, University of London, United Kingdom \\ Francesca Gowing \\ Kingston University and St George's, University of London, United Kingdom \\ Michael English \\ Kingston University and St George's, University of London, United Kingdom \\ Anne-Marie Hassenkamp \\ Kingston University and St George's, University of London, United Kingdom
}

\begin{abstract}
Healthcare programmes tend to neglect exploring self-care strategies for students whilst they are on their clinical placements. There is evidence that students experience placements as challenging because of the long hours, and endeavouring to meet the needs of many patients across diverse challenging settings. Mindfulness is a potential self-management strategy to enable students to manage the challenges and resultant stress during these times, and to work optimally within their competences. This study explores the role of mindfulness in attempting to meet these challenges. Purposive sampling was used to recruit nineteen MSc pre-registration physiotherapy students who received a two-hour mindfulness intervention prior to commencing their placement, and were encouraged to practice mindfulness for 30 minutes three times a week with a CD whilst on placement or in their own time. Additionally, they were asked to practice for 10-15 minutes 'mindfulness of the breath' during this period. A qualitative approach that incorporated thematic analysis was used to analyse the audio-recorded and transcribed pre- and post-placement focus groups. Perceived benefits from practising mindfulness were: a lessening of intrinsic stress, and an ability to cope with extrinsic stress with increased clarity and objectivity. The CD proved burdensome amongst the students, largely owing to time constraints, but this did not deter their desire to implement mindfulness during this time, and they devised alternative and individual modes of practicing this mind-body-based approach. This study lends evidence to support inclusion of mindfulness into the physiotherapy curriculum as a self-management strategy to empower students to cope with clinical placement associated stress.
\end{abstract}

Keywords: mindfulness; physiotherapy students; resilience; self-care; stress

${ }^{*}$ Corresponding Author: Di Thomson, Department of Rehabilitation Sciences, Faculty of Health, Social Care and Education, Kingston University and St George's, University of London, Cranmer Terrace, London SW17 ORE United Kingdom.

Journal URL: http://e-learning.coventry.ac.uk/ojs/index.php/pblh

Thomson, D., Gowing, F., English, M., and Hassenkamp, A.-M. (2017) 'Exploring the role of mindfulness as a potential self-management strategy for physiotherapy students when on clinical placement'. International Journal of Practice-based Learning in Health and Social Care, 5 (2), 19-37 


\section{๑๐ఠ。} This Open Access article is distributed under the terms of the Creative Commons Attribution AttributionNon-Commercial No Derivatives 4.0 International License (https://creativecommons.org/licenses/by-ncnd/4.0/ ), which permits unrestricted non-commercial use, distribution, and reproduction in any medium, provided the original work is properly cited and is unaltered. 


\section{Introduction}

Practice placements are an essential component of physiotherapy students' learning and development, they closely mirror a typical working environment once they qualify and is it here that professional socialisation begins (Miller and Solomon 2002). Students have to deal with the pressure of working long hours and meeting the needs of many patients across diverse challenging settings. For a number of students, this will be the first exposure to the world of work and it is hoped that effective strategies of self-management are established early.

The majority of students and clinical educators view placement experiences as enjoyable (Thomson et al. 2017) and in a very positive light (Hall, McFarlane, and Mulholland 2012). However, a 'theory-practice' gap is acknowledged and, rather than a seamless transition, it can be challenging 'translating' academic knowledge into real-life situations (Newton et al. 2009). Unlike the structured and monitored framework of university (Whiteside, Stubbs, and Soundy 2014), students encounter both formal and informal learning opportunities (Brown et al. 2011) and have the challenge of adapting to new and unpredictable situations (Thomson et al. 2017). In a study by Thomson et al. (2014) exploring how prepared physiotherapy students felt before their first clinical placement, $48 \%$ perceived that the training they received for communicating with families and carers was inadequate, and $24 \%$ felt a lack of interaction with patients and service users before their clinical placement and concluded that this was a limitation. Record keeping, clinical reasoning and goal setting were other areas where students felt ill-prepared. Very importantly, the students experienced feelings of conflict between striving for ideal 'patientcentred care' and having to 'negotiate a different paradigm' in real-world practice (Thomson et al. 2014).

Clinical educators are increasingly concerned about how physiotherapy students deal with the stress they experience whilst on clinical placements (Tucker et al. 2006). Extensive research has explored such stresses in medical and nursing students, but there is a paucity of research specifically focusing on physiotherapy students (Tucker et al. 2006). One exception is a study by Delany et al. (2015) who introduced resilience strategies drawn from cognitive behavioural therapy, and performance psychology.

Whilst moderate amounts of stress can enhance efficiency and memory; the opposite is true of excessive amounts (Yerkes and Dodson 1908). Mental health problems are commonly associated with high levels of stress (Firth 1986, Guthrie et al.1998). Clinical practice placements have been criticised for engendering overly self-critical and self-sacrificing traits in healthcare professionals who may struggle to find a healthy balance between their work and leisure time (Miller and McGowen 2000). Healthcare programmes tend to neglect exploring selfcare strategies for students in these periods assuming that it is an individual responsibility (Chambers et al. 2006). In Gibbons' (2010) study exploring the coping resources used by nursing students, avoidance-coping was the strongest predictor of burn-out. Burn-out, in turn, can have negative consequences for the quality of care received by patients (Irving, Dobkin, and Park 2009), it is associated with decreased patient satisfaction and longer recovery times (Vahey et al. 2004). It is possible that the increased pressure to meet the needs of patients will significantly impair health professionals' decision-making skills, empathy, and ability to build rapport with patients (Beddoe and Murphy 2004). Initiatives to promote support and self-efficacy have been found to be beneficial in improving student well-being (Gibbons 2010), and one of these is mindfulness.

Mindfulness is at 'the heart' of Buddhist meditation (Thera 1962), and helps to cultivate qualities of attention and awareness (Baer 2003). It has been defined as "the awareness that emerges through paying attention, on purpose, in the present moment and non-judgmentally to the unfolding of experience moment by moment" (Kabat-Zinn 2003: 145). Mindfulness is believed to help us connect to the way we are feeling, and accept and overcome negative states without directly affecting the cause of stress (Shapiro et al. 2005, Flook et al. 2013). In contrast to cognitive behavioural approaches which replace 'maladaptive beliefs' with constructive, positive thinking, mindfulness entails observing and noticing without reacting to or intentionally altering 
the experience as it is happening (Segal, Williams, and Teasdale 2002). Mindfulness is completely secular in that it is non-spiritual, and mindfulness-based therapies are now prescribed on the National Health Service for a range of conditions such as depression, irritable bowel syndrome, multiple sclerosis and stable angina (National Institute of Clinical Excellence [NICE] 2008, 2009, 2011, 2014). As an example of the wider application of mindfulness, the United Kingdom (UK) all-party parliamentary group on mindfulness recommend secular meditation courses be made available to young people suffering relapses of depression in schools (to reduce misbehaviour and improve academic results), as well as those in prison and on probation to reduce re-offending (Booth 2015).

Most published research recommends mindfulness training programmes of eight sessions over two months in the form of mindfulness-based stress reduction (MBSR) or mindfulness-based cognitive therapy (MBCT) (Glass 2016). The standard MBSR curriculum requires 45 minutes of individual practice, six days a week (Santorelli and Kabat-Zinn 2009). Whilst there is a lack of research on mindfulness training for physiotherapy students, studies involving healthcare students or healthcare professionals provide supporting evidence for a range of benefits including for stress (Grossman et al. 2004); emotional exhaustion and depersonalisation (Cohen-Katz et al. 2005); mental health (Shapiro et al. 2005, Epstein-Lubow et al. 2011, Barbosa et al. 2013); and empathy (Beddoe and Murphy 2004). Expressing empathy has been associated with positive outcomes for both clinicians and patients alike (Duarte, Pinto-Gouveia, and Cruz 2016), although in excess may be a risk factor for compassion fatigue. Selfcompassion, believed to be a key mediator of mindfulness (Kuyken et al. 2010), helps regulate the relationship between affective empathy and compassion fatigue. Self-compassion is correlated with insight, self-awareness, kindness, optimism and initiative (Neff, Rude, and Kirkpatrick 2007). Mindfulness therefore supports recommendations of The Francis Report (Francis 2013) for a more caring and compassionate workforce.

A systematic review by Lomas, Ivtzan, and Fu (2015) showed evidence for the co-presence of elevated alpha and theta waves during mindfulness, thought to indicate a state of 'relaxed alertness' (Britton et al. 2014) beneficial to mental health. Mindfulness enables individuals to have an increased awareness of the target of their focus. This could be the breath, sensations coming from their surroundings, their body or their thoughts and feelings (Lutz et al. 2008). This process of deliberate attention is associated with areas in the cortex which are also responsible for empathy and compassion (Lutz et al. 2008).

There have been very few studies in physiotherapy that have explored the role of mindfulness as a potential self-management strategy to enable physiotherapy students to manage their stress and to work optimally within their competences. Thomson et al. (2014) asked physiotherapy students to identify causes of stress on their placements, and found that time constraints, relationships with clinical educators, interactions with patients, and record keeping were all sources of stress. Therefore, it is important to find ways of reducing the psychological and physiological manifestations of stress in students, and this study sought to explore if mindfulness could be instrumental in combating the effects of stress on physiotherapy students' emotional and physical well-being.

\section{Method}

\section{Research design}

A descriptive qualitative design was used to explore MSc pre-registration physiotherapy students' experiences of practising mindfulness whilst on their clinical placements.

\section{Data collecting instrument}

Focus groups were used to collect data on perceptions, understanding, ideas, attitudes, and feelings on a particular topic via interaction between participants (Kitzinger 1995). Such group 
interaction can encourage participants to develop and refine their thoughts, and can reveal more about the understanding of a complex issue compared with individual interviews or questionnaires (Plummer-D'Amato 2008). Focus group key questions were prepared in advance to ensure the discussion developed naturally towards significant issues (Appendix 1). The group facilitator used a triangular questioning structure, as proposed by Hurworth (1996) with broad opening questions (base of triangle) to allow participants to construct meaning of their situation (Lincoln, Lynham, and Guba 2011), succeeded by 'transition' questions, progressing to the key question (apex of triangle). The facilitator endeavoured to maintain the focus of the discussion without endorsing or constraining a particular viewpoint, and to manage those most verbal, unobtrusively, whilst encouraging quieter participants (Sim and Snell 1996). A second group facilitator observed, and took notes on, non-verbal behaviour.

\section{Participants}

Nineteen final year MSc pre-registration physiotherapy students with an age range of 23 to 28 years were invited to take part in the study, and nine volunteered. All were enrolled at a large metropolitan university in the UK, and had completed four clinical practice placements.

Purposive sampling was used in this study to satisfy inclusion criteria of final year MSc (pre-reg) physiotherapy students who were studying at a large metropolitan university in the UK, and had completed four clinical practice placements. Furthermore, homogeneity of participants with respect to year and level of study contributed to people feeling comfortable voicing opinions (Morgan 1992), and lessened any effects of status differentials (Kitzinger 1995).

Choice of group size followed the recommended size of six to eight (Chestnutt and Robson 2001, Krueger and Casey 2015) with one extra participant to allow for any absence. Final year students were chosen because previous stress on placement might prompt students to be open to try mindfulness to relieve stress, and to persevere with it. Having done more than one placement gives students some sort of benchmark for comparison of stress levels. Often, it is only on reflection that stress can be identified. The conductors of the focus groups were not staff members as it was thought that this could restrict the spontaneity of the responses.

\section{Procedure}

Prior to their fifth clinical practice placement, participants attended a one-hour pre-placement focus group to establish the experience of stress on placement, and then to explain the role of mindfulness in addressing it. Subsequently, they attended a two-hour mindfulness training session led by an academic trained in Cognitive Behavioural Therapy who had attended an eight week course entitled Mindfulness-based Cognitive Therapy. This course consists of bodyscan meditation, breathing meditation and mindful movement meditation, as a way to reduce stress and transform the way one responds to problems and challenges. The participants were provided with a mindfulness CD, (an adaptation of one supplied by the course), and were invited to practise mindfulness using the $C D$ for thirty minutes, two to three times a week whilst they were on their clinical placements. They were also asked to practice for 10-15 minutes 'mindfulness of the breath' during this period, either in the clinical setting or at home. On completion of their clinical practice placement, participants were invited to attend an approximately one-hour audio-taped focus group exploring the effect of mindfulness on their ability to handle possible stressors on placement.

The focus groups were conducted in a quiet meeting room. The room was arranged with participants seated facing each other and spaced evenly around a central table, ensuring eye contact between all participants (Krueger and Casey 2015). 
In this study, various strategies were put into place to address trustworthiness. The purpose of the study was to accurately represent the voices of the participants, and the transcripts of the focus groups were given to the participants to confirm that they were an accurate representation of what took place as well as giving them an opportunity to clarify or expand on what they recounted. Additionally, the analysis was performed individually by the researchers, then compared, and then peer-reviewed by a colleague who was knowledgeable in qualitative research. The aim of qualitative research is for readers to find resonance in the interpretations and context, and to consider their relevance to their own practice.

\section{Data analysis}

The focus group was transcribed verbatim by the researchers. Transcripts were read by the researchers while listening to the corresponding audio recording to ensure accuracy (Braun and Clarke 2006). Braun and Clarke's (2006) work on thematic analysis underpinned the approach used in this study. The transcripts were each read through in their entirety, and then re-read several times to ensure familiarity and to immerse the researchers in the data. Line-by-line coding was completed to identify semantic features of the data (Braun and Clarke 2006). These codes were then grouped, based on their relationship to one another. At this point, the researchers compared their analyses, and produced an initial theme map. They refined this further, and combined the themes to form themes and sub themes, and this resulted in a final theme map (Figure 1).

Figure 1: Theme map showing the four main themes and their subthemes that arose from the thematic analysis

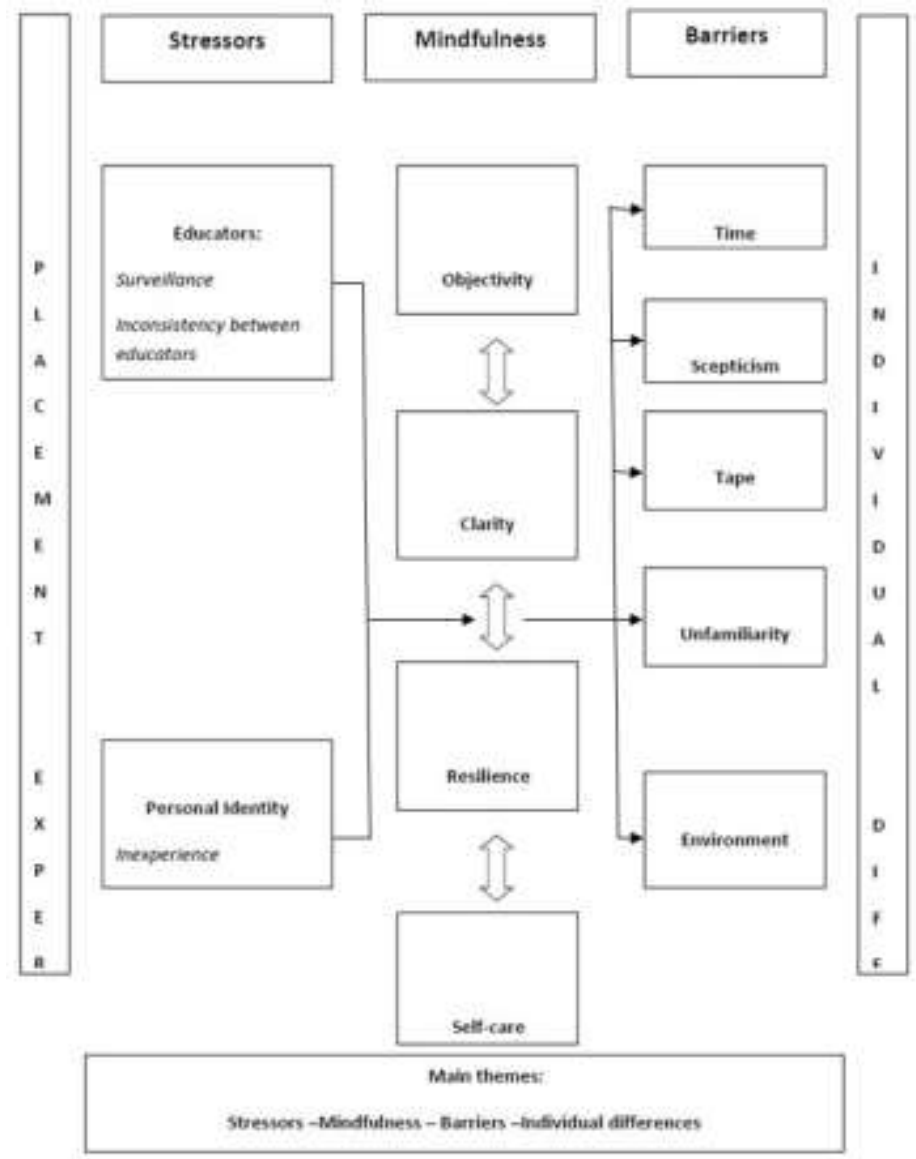




\section{Findings}

The students' experience of mindfulness matched with many of the theorised, and therefore predicted, benefits of mindfulness such as self-control, emotional regulation, flexible thinking, positivity, kindness, and acceptance (Davis and Hayes 2011). However, four themes stood out as a result of practising mindfulness: objectivity, clarity, resilience and self-care (see Figure 1).

\section{Objectivity}

Increased objectivity was commonly identified by participants, for some, leading to less reactivity, increased positive thinking, and productivity.

I adapted my way of thinking or how I would approach a situation (FG2_L13_p3_student3)

Before I found when I was getting home without even knowing 2-3 hours of the evening had passed and I was in a bad mood about the stupid bus...but when I used positive thinking, I thought, 'l've got my whole evening ahead of me' and I was a bit more productive (FG2_L13_p11_student5)

\section{Clarity}

Many students spoke of mindfulness as having helped them to pause and reflect when feeling overwhelmed or when aware of negative ruminations impinging on behaviour. By providing a distance between themselves and the patient, mindfulness helped the students to disengage from a mind full of racing thoughts and focus.

I couldn't think and was getting really frustrated not being able to work out what was wrong so I literally took myself out of the situation and kind of gathered my thoughts... and then went back and felt more composed. (FG2_L28_p5_student3)

Mindfulness could be seen as a way of letting go of emotional ties such as empathy and regaining a sense of self.

it is like a weird emptying of the brain but filling it with me...rather than things...a sense of yeah, how l'd deal with things and my action plan (FG3_L19_p14_student6)

Indeed, unchecked, excess empathy may cloud judgement (Sultan-Haque, and Waytz 2011). For some, mindfulness heightened awareness to nature or physical sensations.

things like rain, stuff that you just take for granted because it is a background noise (FG2_L13_p12_student9)

I just tried to cycle and focus on the motion of my legs and just think ok so it's my quads that are working, my quads that are working.. I realised that I had a moment of not thinking about placement...or whatever else was going on...I was just thinking about the cycling...so it was quite nice (FG3_L18_p4_student2)

Other individuals experienced a numbing of senses, whilst gaining deeper mental focus.

It was to do with the stillness and staying still for that amount of time and I ... lost all awareness of where my arms were in space...I was entirely focusing inwards (FG3_L22_p5_student1)

\section{Resilience}

Some of the students acknowledged that mindfulness helped foster a sense of resilience. 
Mindfulness was more a way of helping to avoid stress rather than deal with it when it was actually there (FG3_L2_p6_student8)

Rather than resisting or reacting to stressful circumstances; there was increased acceptance.

The less you feel...stressed...I felt I could deal with this placement as it was going (FG 3_L43_p5_student1)

McCann and colleagues (2013) define resilience as the ability to maintain personal and professional wellbeing in the face of ongoing work stress and adversity. They advocate resilience-promoting behaviours for healthcare professionals as a means of preventing burn-out and symptoms of traumatic stress.

\section{Self-care}

The students drew parallels between mindfulness and self-care, and inner compassion.

It gave me the opportunity just to make more time for myself really, do things you enjoy (FG3_L2_p14_student8)

I felt more allowed to not be studying in the evening...to not be thinking about the day (FG3_L19_p11_student1)

Eltringham, Gill-Cripps, and Lawless (2000) note the NHS cultural tendency for staff to attend to patients' needs ahead of their own. Gillbert (2001) refers to this as "selfless obligation" (204). Self-care encompasses deliberate actions taken to care for physical, emotional, and mental health. Likewise, Richards, Campenni, and Muse-Burke (2010) view self-care as ethically crucial for healthcare professionals to guard against any detrimental effects of burn-out on patient care. In the pre-intervention focus group, students spoke of a variety of existing methods for dealing with stressors on placement. Rather than replace established coping mechanisms, mindfulness helped encourage the use of self-management strategies.

On placement, I use positive affirmations a lot so I set alarms on my phone to say something positive...I think that mindfulness kind of encourages you to do it more (FG2_L41_p13_student4)

For many students, mindfulness was conducive to sleep.

I don't go straight to sleep, so I did it when I was lying there and found it quite useful for relaxing (FG2 L40_p3 student5)

A study by Kemper, Mo, and Khayat (2015) found sleep and resilience to be significantly correlated with mindfulness and compassion. After controlling for stress and mental health however, mindfulness was no longer significantly related to resilience or sleep. A possible explanation is that mindfulness does not directly affect sleep or resilience but does so primarily via changes in mental health or perceived stress.

\section{Barriers to practising mindfulness}

\section{Time}

Confronted with limited free time on placement, several students found it a juggling act to fit mindfulness around their already hectic routines, as well as finding time to socialise with friends and family. 
I just felt very tired for a lot of it, kind of exhausted. It felt like I was getting home and I had about two hours in between getting home and going to bed (FG3_L4_p14_student1)

I just wanted to sit on the sofa and fill my mind with useless things and sharing time with other people like my other half, I had to see him (FG3_L29_p1_student6)

\section{Scepticism}

In conjunction with limited personal time available on placement, a cost-benefit analysis often determined likelihood to practice mindfulness. Where scepticism was high, costs might outweigh the perceived benefits.

Not trusting that it was going to do anything I guess. And so not, I mean to invest the time in it, because the time could be spent better...looking at more journals or reflecting or whatever (FG2_L15_p2_student7)

Alternatively, the ability to 'buy into' mindfulness and trust in the benefits were facilitative to its practice.

You can't force yourself to be mindful and benefit from it...you have to have that idea beforehand that you will benefit from it and that it will be useful

(FG2_L36_p15_student4)

\section{Aids to practising mindfulness}

In general, the CD was not deemed a useful method of sustaining long-term practice of mindfulness. Everyone found the length of 30 minutes, three times a week was unrealistic to fit into the demanding routine of placement both during and in their own time; and there was consensus that mindfulness should not be prescriptive, but something that could be tailored to individual needs.

I would sort of recommend seeking your own kind of form of mindfulness whether it be like a particular sound or a song or umm being out in nature, breathing whatever, just finding the thing that works for you (FG3_L21_p15_student8)

However, it was recognised that the CD gave a useful introduction to the practice.

Maybe to start with something where it is leading you and then to kind of have an appreciation a bit and then to be able to do it on your own (FG3_L3_p14_student1).

\section{Unfamiliarity}

For those with no previous experience, mindfulness might be seen as something additional to get used to on top of a whole new setting and team.

In the first two weeks...it's hard to remember to do extra things (FG2_L43_p4_student9)

A study by Lally et al. (2010) demonstrated an average of 66 days is required for habit formation, that is, for behaviour to become automatic in response to contextual cues (Neal et al. 2012). Gardner, Lally, and Wardle (2012) views habit formation as 'cognitively efficient' in freeing mental resources for alternative tasks.

I kind of got into the habit of doing that (mindfulness) and I think that was easier (FG2_L22_p10_student9) 


\section{Established coping mechanisms}

Where students already had established strategies which they considered effective at combating, stress, it might be harder for them to 'buy into' the idea of mindfulness.

I was cycling 20 miles a day so that was my chance to de-stress if I was feeling any (FG3_L24_p11_student2)

That is what I always do...talk about it to somebody impartial and use that as one of my coping strategies (FG2_L10_p20_-student7)

For others, mindfulness helped reinforce existing self-management strategies.

\section{Environment}

Some placement settings were considered more conducive to practice of mindfulness than others. On a community placement, the lack of private space to practise mindfulness was seen as a barrier.

I was never in a room on my own for 10 minutes (FG2_L37_p8_student7)

In a musculoskeletal setting, whilst the availability of a 30 minute block to practise mindfulness was deemed unrealistic, it was feasible that there might be small pockets in the day in which to practise.

a few minutes after the morning or say when you've got a patient who does not arrive (DNA) (FG2_L21_p7_student3)

\section{Individual differences}

Interestingly, the students practised mindfulness based on their individual interpretations of mindfulness, own adaptations of skills gained from the CD and intervention session, previous experience, and according to available time in their personal and clinical routines. Some students downloaded shorter apps of 10-15 minutes which they practised two to three times a week, others simply tried to 'switch off' more and practise in their heads when alone such as on a train commute. A few were able to integrate mindfulness into a challenging event on placement, as it occurred. This has parallels with reflection-in-action (Schön 1983) which involves thinking on one's feet at the time of an event to connect with one's feelings and gain insight into the situation rather than acting impulsively.

I had a situation where I was shouted at like l've never been talked to in my life...I tried to employ mindfulness at that point just by being completely flabbergasted that someone was doing that to my face...just not let's compute what is going on here and let's focus on breathing and where you are in space and try and understand the situation like that (FG3_L44_p4_student6)

Some students found a group approach helped provide discipline and structure to the practice, especially initially.

It felt like a kind of joined experience and it felt like we were both putting this time aside properly ...to start off with, I feel like it's easier, it made it more accessible having a partner to do it with (FG3_L11_p16_student1)

Others preferred to practice independently.

I think mindfulness is quite complex but also very personal to each individual and I prefer doing it on my own (FG3_L25_p16_student8) 
Another method was to incorporate mindfulness into another activity such as yoga or running. Research by Alderman and colleagues (2016) indicated a combination of aerobic exercise and meditation may be effective in combating depression while enhancing cognitive processing.

it felt like a nice way of...treating my mind and treating my body (FG3_L3_p10_student1)

By discussing individual interpretations of mindfulness in the focus group, some individuals identified that they subconsciously practised mindfulness.

I think I do employ it without realising sometimes and then I find myself just being like just focussing and chilling out (FG3_L14_p15_student6)

\section{Discussion}

This study initially explored the participants' experience of stress in previous placements in order to be open to try mindfulness (to relieve stress), and to persevere with it. Often it is only in hindsight that stress can be identified. An overarching cause of stress for the students on clinical placement emanated from the assessment process and the associated insecurity of being in transition from a student to a professional.

While the utility of the 30 minute $C D$ as a mode of practice of mindfulness was burdensome, this group of students was innovative in individualising their approach. Indeed, in contrast to a onepointed meditation, mindfulness has been described as 'openness to all experiences' (Shapiro, Schwartz, and Bonner 1998) suggesting greater flexibility in practice. It is equally possible that other students might feel confined to practice mindfulness according to the CD. Interestingly, some students identified a 'baseline' subconscious practice of mindfulness, even those who were initially sceptical. A valid aspect of training would be to make individuals more self-aware of how they might already be mindful and how to nurture those skills, in turn enhancing selfawareness through mindfulness. Indeed, Kabat-Zinn (2003) considers mindfulness an 'inherent human capacity' which all humans do to an extent, moment-by-moment. Furthermore, selfawareness is considered to be important to foster in physiotherapists, in order for them to be perceptive and attentive to the needs of others (Josselson 1996), and is a prerequisite for critical reflection (McKinnon 2016).

Following the mindfulness intervention and subsequent practice of mindfulness by students during their placement, a myriad of theorised benefits (Davis and Hayes 2011) were apparent. Benefits were specific to the individual, and mostly related to themes of objectivity, clarity, resilience or self-care. No negative effects of mindfulness were reported, but some individuals found it more effective than others. De Vibe et al. (2015) explored whether certain personalities are more likely to benefit from mindfulness interventions. They conducted a randomised controlled trial of mindfulness-based stress reduction on 288 medical and psychology students. Mindfulness training was most effective in those with higher conscientiousness scores; and women scored significantly higher on conscientiousness and neuroticism, indicating they may be an important target group for interventions. Sharkley and Sharples (2003) posited that some students who pursue careers in the caring professions may have higher baseline rates of anxiety and depression increasing their susceptibility to placement stressors from the outset.

Whilst the practise of mindfulness might not be able to influence some of the extrinsic stresses (Flook et al. 2013); by encouraging more objective thinking and challenging ingrained perspectives, there was a higher level of acceptance of extrinsic and often uncontrollable stresses and a corresponding decrease in intrinsic stresses such as guilt with not promoting self-care and self-management. Fitting with previous studies of mindfulness (Kabat-Zinn 1993), the students appeared more likely to approach stressful events as challenges instead of threats.

Students who embraced mindfulness wholeheartedly, tended to be those who had some baseline experience of mindfulness or meditation and had previously found it beneficial. These 
students were able to integrate it into their day on placement when various pressures presented. Those more sceptical about the benefits of mindfulness, tended to place it low on priorities when faced with a new or unexpected experience on placement.

\section{Limitations}

This research was undertaken at one university with nine volunteers thus limiting the generalisability of insights to other universities and to the large number of students enrolled in these universities, however, clinical practice experience is uniform throughout the study of physiotherapy. It would also have been advantageous to explore the effect of a follow-up period to see if the students had maintained their mindfulness practice in further clinical placements and this could be the basis of future studies.

\section{Conclusion}

Physiotherapy students are subject to high levels of extrinsic stress on clinical placement, accentuated by high levels of intrinsic stress. By fostering resilience and self-care, mindfulness helped students lessen intrinsic stresses and approach extrinsic stresses with increased clarity and objectivity. Beneficial effects with the practice of mindfulness were seen amongst all students in varying amounts, even those initially sceptical who were later able to identify subconscious practice. The study provides evidence to support the case for inclusion of mindfulness into the physiotherapy curriculum as has been recommended for UK medical schools (General Medical Council 2015). Currently, every second-year student has to complete a reflective portfolio as part of their clinical practice; and, as a result of this research, mindfulness practice has been incorporated in this module in the study university. As time was the biggest barrier to practice of mindfulness for students, it is likely that adapting a briefer intervention such as 'mindfulness of the breath' would be most suitable (MacKenzie, Poulin, and Seidman-Carlson 2006)

Early introduction to the practice of mindfulness before clinical practice would be advantageous (Ying 2008) in order to help students develop robust self-management skills for the future and protect against symptoms of burn-out (Irving, Dobkin, and Park 2009). In turn, this may help students maintain personal and professional wellbeing amidst continuous work stressors (Gibbons 2010) and ultimately, enhancing quality of care, empathy and therapeutic relationships (Beddoe and Murphy 2004). Furthermore, personal engagement with mindfulness may enable students to better integrate mindfulness skills and teach them to appropriate patient groups (Marx, Strauss, and Williamson 2014).

\section{Compliance with ethical standards}

Ethical approval: Ethical approval given by the Faculty Research Ethics Committee (FREC 112-2016).

Informed consent: Informed consent was obtained from all individual participants included in the study.

Conflict of interest: The authors declare that they have no conflict of interest.

\section{Acknowledgements}

We are grateful to the participants for giving their time to this study. 


\section{References}

Alderman, B.L, Olson, R.L., Brush, C.J., and Shors, T.J. (2016) 'MAP Training: Combining meditation and aerobic exercise reduces depression and rumination while enhancing synchronised brain activity'. Translational Psychiatry, 6, e726 https://doi.org/10.1038/tp.2015.225

Baer, R.A. (2003) 'Mindfulness training as a clinical intervention: A conceptual and empirical review'. Clinical Psychology: Science and Practice, 10: 125-143 doi:10.1093/clipsy.bpg015

Barbosa, P., Raymond, G., Zlotnick, C., Wilk, J., Toomey, R., and Mitchell, J. (2013) 'Mindfulness-based stress reduction training is associated with greater empathy and reduced anxiety for graduate healthcare students'. Education for Health, 26(1), 9-14 https://doi.org/10.4103/1357-6283.112794

Beddoe, A.E., and Murphy, S.O. (2004) 'Does mindfulness decrease stress and foster empathy among nursing students?' Journal of Nursing Education, 43, 305-312 doi:10.3928/01484834-20040701-07

Booth (2015) 'Mindfulness in the mainstream: An old solution to modern problems'. The Guardian [online] 20 October. available from: https://www.theguardian.com/lifeandstyle/2015/oct/20/mindfulness-in-the-mainstreaman-old-solution-to-modern-problems [4 November 2015]

Braun, V. and Clarke, V. (2006) 'Using thematic analysis in psychology'. Qualitative Research in Psychology, 3 (2), 77-101 https://doi.org/10.1191/1478088706ap063oa

Britton, W.B., Lepp, N.E., Niles, H.F., Rocha, T., Fisher, N.E., and Gold, J.S. (2014) 'A randomized controlled pilot trial of classroom-based mindfulness meditation compared to an active control condition in sixth-grade children'. Journal of School Psychology, 52 (3), 263-278 https://doi.org/10.1016/i.jsp.2014.03.002

Brown, T., Williams, B., McKenna, L., Palermo, C., McCall, L., Roller, L., ... and Aldabah, L. (2011) 'Practice education learning environments: The mismatch between perceived and preferred expectations of undergraduate health science students'. Nurse Education Today, 31 (8), e22-e28 https://doi.org/10.1016/j.nedt.2010.11.013

Chambers, J.C., Christopher, S.E., Dunnagan, T., and Schure, M. (2006) 'Teaching self-care through mindfulness practices: The application of yoga, meditation and qigong to counselor training'. Journal of Humanistic Psychology, 46, 494-509 https://doi.org/10.1177/0022167806290215

Chestnutt, I.G., and Robson, K.F. (2001) Focus groups - what are they? Dental Update, 28 (4), 189-192 https://doi.org/10.12968/denu.2001.28.4.189

Cohen-Katz, J., Wiley, S. D., Capuano, T., Baker, D. M., and Shapiro, S. (2005) 'The effects of mindfulness-based stress reduction on nurse stress and burnout, Part II: A quantitative and qualitative study'. Holistic nursing practice, 19 (1), 26-35

https://doi.org/10.1097/00004650-200501000-00008

Davis, D. and Hayes, J. (2011) 'What are the benefits of mindfulness? A practice review of psychotherapy-related research'. Psychotherapy, 48 (2), 198-208

https://doi.org/10.1037/a0022062 
Delany, C., Miller, K. J., El-Ansary, D., Remedios, L., Hosseini, A., and McLeod, S. (2015). Replacing stressful challenges with positive coping strategies: A resilience program for clinical placement learning. Advances in Health Sciences Education, 20 (5), 1303-1324 https://doi.org/10.1007/s10459-015-9603-3

De Vibe, M., Solhaug, I., Tyssen, R., Friborg, O., Rosenvinge, J.H., Sørlie, T. ... Bjørndal, A. (2015) 'Does personality moderate the effects of mindfulness training for medical and psychology students?' Mindfulness, 6, 281-289 https://doi.org/10.1007/s12671-013$\underline{0258-y}$

Duarte, J., Pinto-Gouveia, J., and Cruz, B. (2016) 'Relationships between nurses' empathy, selfcompassion and dimensions of professional quality of life: A cross-sectional study'. International Journal of Nursing Studies, 60, 1-11 https://doi.org/10.1016/j.ijnurstu.2016.02.015

Eltringham, D., Gill-Cripps, P., and Lawless, M. (2000) 'Challenging values in clinical supervision through reflective conversations'. in Effective Clinical Supervision: The Role of Reflection. ed. by Ghaye, T. and Lillyman, S., Wiltshire, UK: Quay Books, 19-44

Epstein-Lubow, G., McBee, L., Darling, E., Armey, M., and Miller, I.W. (2011) 'A pilot investigation of mindfulness-based stress reduction for caregivers of frail elderly'. Mindfulness, 2, 95-102 https://doi.org/10.1007/s12671-011-0047-4

Firth, J. (1986). Levels and sources of stress in medical students. British Medical Journal (Clin Res Ed), 292 (6529), 1177-1180 https://doi.org/10.1136/bmj.292.6529.1177

Flook, L., Goldberg, S.B., Pinger, L., Bonus, K., and Davidson, R.J. (2013) 'Mindfulness for teachers: A pilot study to assess effects, on stress, burnout, and teaching efficacy'. Mind, Brain and Education, 7 (3), 182-195 https://doi.org/10.1111/mbe.12026

Francis, R. (2013) Report of the Mid Staffordshire NHS Foundation Trust Public Inquiry. London: The Stationery Office

Gardner, B., Lally, P., and Wardle, J. (2012) 'Making health habitual: The psychology of 'habitformation' and general practice'. British Journal of General Practice, 62 (605), 664-666 https://doi.org/10.3399/bjgp12X659466

General Medical Council (2015) Supporting Medical Students with Mental Health Conditions [online] available from: http://www.gmcuk.org/Supporting students with mental health conditions 0816.pdf 53047904.pdf [16 October 2017]

Gibbons, C. (2010) 'Stress, coping and burn-out in nursing students'. International Journal of Nursing Studies, 47, 1299-1309 https://doi.org/10.1016/.ijnurstu.2010.02.015

Gilbert, T. (2001) 'Reflective practice and clinical supervision: Meticulous rituals of the confessional'. Journal of Advanced Nursing, 36, 199-205 doi:10.1046/j.13652648.2001.01960.x https://doi.org/10.1046/j.1365-2648.2001.01960.x

Glass, K. (2016) 'Clinical update: Mindfulness'. Frontline, 22 (3), 28-29

Grossman, P., Niemann, L., Schmidt, S., and Walach, H. (2004) 'Mindfulness-based stress reduction and health benefits: A meta-analysis'. Journal of Psychosomatic Research, 57 (1), 35-43 https://doi.org/10.1016/S0022-3999(03)00573-7 
Guthrie, E., Black, D., Bagalkote, H., Shaw, C., Campbell, M., and Creed, F. (1998) 'Psychological stress and burnout in medical students: A five-year prospective longitudinal study'. Journal of the Royal Society of Medicine, 91, 237-243 https://doi.org/10.1177/014107689809100502

Hall, M., McFarlane, L., and Mulholland, S. (2012) 'Positive clinical placements: Perspectives of students and clinical educators in rehabilitation medicine'. International Journal of Therapy and Rehabilitation, 19 (10), 549-556 https://doi.org/10.12968/ijtr.2012.19.10.549

Hurworth, R. (1996) 'Qualitative methodology: Common questions about running focus groups during evaluations'. Evaluation News and Comments, 5 (1), 40-52

Irving, J.A., Dobkin, P.L., and Park, J. (2009) 'Cultivating mindfulness in health care professionals: A review of empirical studies of mindfulness-based stress reduction (MBSR)'. Complementary Therapies in Clinical Practice, 15, 61-66 https://doi.org/10.1016/j.ctcp.2009.01.002

Josselson, R. (1996) The Space Between Us: Exploring the Dimensions of Human Relationships. Thousand Oaks, CA: Sage

Kabat-Zinn, J. (1993) 'Mindfulness meditation: Health benefits of an ancient Buddhist practice'. in Mind/Body Medicine. ed. by Goleman, D. and Gurin, J. New York: Consumer Reports Books, 259-275.

Kabat-Zinn, J. (2003) 'Mindfulness-based interventions in context: Past, present, and future'. Clinical Psychology: Science and Practice, 10, 144-156 doi:10.1093/clipsy.bpg016 https://doi.org/10.1093/clipsy.bpg016

Kemper, K.J., Mo, X., and Khayat, R. (2015) 'Are mindfulness and self-compassion associated with sleep and resilience in health professionals?' The Journal of Alternative and Complementary Medicine, 21 (8), 496-503 https://doi.org/10.1089/acm.2014.0281

Kitzinger, J. (1995) 'Qualitative research: Introducing focus groups'. BMJ, 311, 299-302 https://doi.org/10.1136/bmj.311.7000.299

Krueger, R.A. and Casey, M.A. (2015) Focus Groups: A Practical Guide for Applied Research. 5th edn. Thousand Oaks: Sage

Kuyken, W., Watkins, E., Holden, E., White, K., Taylor, R., Byford, R. ... Dalgleish, T. (2010) 'How does mindfulness-based cognitive therapy work?' Behaviour Research and Therapy, 48, 1105-1112 https://doi.org/10.1016/j.brat.2010.08.003

Lally, P., Van Jaarsveld, C.H.M., Potts, H.W.W., and Wardle, J. (2010) 'How are habits formed: Modelling habit formation in the real world?' European Journal of Social Psychology, 40, 998-1009 doi:10.1002/ejsp.674 https://doi.org/10.1002/ejsp.674

Lincoln, Y., Lynham, S., and Guba, E.G. (2011) 'Paradigmatic controversies, contradictions, and emerging confluences revisited'. in The Sage Handbook of Qualitative Research. 4th edn. ed. by Denzin, N. and Lincoln, Y. Thousand Oaks, CA: Sage, 97-128

Lomas, T., Ivtzan, I., and Fu, C.H.Y. (2015) 'A systematic review of the neurophysiology of mindfulness on EEG oscillations'. Neuroscience and Biobehavioral Reviews, 57, 401410 https://doi.org/10.1016/..neubiorev.2015.09.018 
Lutz, A., Slagter, H.A., Dunne, J., and Davidson, R.J. (2008) 'Attention regulation and monitoring in meditation'. Trends in Cognitive Sciences, 12 (4), 163-169 https://doi.org/10.1016/.tics.2008.01.005

MacKenzie, C.S., Poulin, P.A., and Seidman-Carlson, R. (2006) 'A brief mindfulness-based stress reduction intervention for nurses and nurse aids'. Applied Nursing Research, 19, 105-109 https://doi.org/10.1016/j.apnr.2005.08.002

Marx, R., Strauss, C., and Williamson, C. (2014) 'The eye of the storm: A feasibility study of an adapted Mindfulness-Based Cognitive Therapy (MBCT) group intervention to manage NHS staff stress'. The Cognitive Behaviour Therapist, 7 (e18), 1-17 https://doi.org/10.1017/S1754470X14000300

McCann, C.M., Beddoe, E., McCormick, K., Huggard, P., Kedge, S., Adamson, C., and Huggard, J. (2013) 'Resilience in the health professions: A review of recent literature'. International Journal of Wellbeing, 3 (1), 60-81 https://doi.org/10.5502/ijw.v3i1.4

McKinnon, J. (2016) Reflection for Nursing Life, Principles, Process and Practice. Abingdon, Oxon: Routledge

Miller, M.N. and McGowen, K.R. (2000) 'The painful truth: Physicians are not invincible'. Southern Medical Journal, 93, 966-973 https://doi.org/10.1097/00007611-20009310000004

Miller, P.A., and Solomon, P. (2002) 'The influence of a move to program management on physical therapist practice'. Physical therapy, 82 (5), 449-458

Morgan, D.L. (1992) 'Designing focus group research'. In Tools for Primary Care Research. ed. by Stewart, M., Tudiver, F., Bass, M., Dunn, E., and Norton, P. Thousand Oaks, CA: Sage, $177-193$

National Institute for Health and Care Excellence (2008) p.18 [online] Irritable Bowel Syndrome in Adults: Diagnosis and Management. available from: https://www.nice.org.uk/guidance/cg61/resources/irritable-bowel-syndrome-inadultsdiagnosis-and-management-975562917829 [23 July16]

National Institute Health and Care Excellence (2009) Depression in Adults: Recognition and Management (10) [online] available from https://www.nice.org.uk/Guidance/CG90 [23 July16]

National Institute for Health and Care Excellence (2011) Stable Angina: Management (24) [online] available from https://www. nice.org.uk/guidance/cg126/resources/stableanginamanagement- 35109453262021 [23 July16]

National Institute for Health and Care Excellence (2014) Multiple Sclerosis in Adults: Management (16) [online] https://www.nice.org.uk/guidance/cg186/resources/multiplesclerosis-management-of-multiple-sclerosis-in-primary-and-secondary-care-

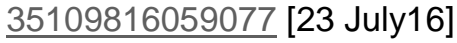

Neal, D.T., Wood, W., Labrecque, J.S., and Lally, P. (2012) 'How do habits guide behaviour? Perceived and actual triggers of habits in daily life'. Journal of Experimental Social Psychology, 48, 492-498 https://doi.org/10.1016/i.jesp.2011.10.011

Neff, K.D., Rude, S.S., and Kirkpatrick, K. (2007) 'An examination of self-compassion in relation to positive psychological functioning and personality traits'. Journal of Research in Personality, 41, 908-916 https://doi.org/10.1016/j.jrp.2006.08.002 
Newton, J.M., Billett, S., Jolly, B., and Ockerby, C.M. (2009) 'Lost in translation: Barriers to learning in health professional clinical education'. Learning in Health and Social Care, 8 (4), 315-327 https://doi.org/10.1111/j.1473-6861.2009.00229.x

Plummer-D’Amato, P. (2008) 'Focus group methodology Part 1: Considerations for design'. International Journal of Therapy \& Rehabilitation, 15 (2), 69-73 https://doi.org/10.12968/ijtr.2008.15.2.28189

Richards, K.C., Campenni, E., and Muse-Burke, J.L. (2010) 'Self-care and well-being in mental health professionals: The mediating effects of self-awareness and mindfulness'. Journal of Mental Health Counseling, 32 (3), 247-264 https://doi.org/10.17744/mehc.32.3.0n31v88304423806

Santorelli, S.F. and Kabat-Zinn, J. (2009) Mindfulness-Based Stress Reduction (MBSR) Professional Education and Training: MBSR Curriculum and Supporting Materials. Amherst, MA: University of Massachusetts Medical School

Schön, D.A. (1983) The Reflective Practitioner: How Professionals Think in Action. Aldershot, UK: Arena Ashgate

Segal, Z.V., Williams, J.M.G.., and Teasdale, J.D. (2002) Mindfulness-based Cognitive Therapy for Depression: A New Approach to Preventing Relapse. New York: Guilford

Sharkley, S.B., and Sharples, A. (2003) 'The impact on work-related stress of mental health teams following team-based learning on clinical risk management'. Journal of Psychiatric and Mental Health Nursing, 10, 73-81 https://doi.org/10.1046/j.13652850.2003.00534.x

Shapiro, S.L., Astin, J.A., Bishop, S.R., and Cordova, M. (2005) 'Mindfulness-based stress reduction for health care professionals: Results from a randomised trial'. International Journal of Stress Management 12 (2), 164-176 https://doi.org/10.1037/1072$\underline{5245.12 .2 .164}$

Shapiro, S.L., Schwartz, G.E., and Bonner, G. (1998) 'Effects of mindfulness-based stress reduction on medical and premedical students'. Journal of Behavioural Medicine, 21 (6), 581-599 https://doi.org/10.1023/A:1018700829825

Sim, J., and Snell, J. (1996) 'Focus groups in physiotherapy evaluation and research'. Physiotherapy, 82 (3), 189-98 https://doi.org/10.1016/S0031-9406(05)66923-4

Sultan-Haque, O., and Waytz, A. (2011) 'Mind: Why doctors should be more empathetic- But not too much more'. Scientific American [online] available from http://www.scientificamerican.com/article/doctors-and-dehumanization-effect/ [21 July16]

Thera, N. (1962) The Heart of Buddhist Meditation. New York: Weiser

Thomson, D., Boyle, D., Legg, C., Owen, M., Newman, M., and Cole, M.J. (2014) 'Clinical placements: The perspective of UK physiotherapy students on how prepared they were by their university for their first clinical placements: An example of one HEl'. The International Journal of Practice-Based Learning in Health and Social Care, 2 (1), 6979 https://doi.org/10.11120/pblh.2014.00031

Thomson, D., Patterson, D., Chapman, H., Murray, L., Toner, M., and Hassenkamp, A.M. (2017) 'Exploring the experiences and implementing strategies for physiotherapy 
students who perceive they have been bullied or harassed on clinical placements: Participatory action research'. Physiotherapy, 103 (1), 73-80 https://doi.org/10.1016/j.physio.2015.12.003

Tucker, B., Jones, S., Mandy, A. and Gupta, R., (2006) 'Physiotherapy students' sources of stress, perceived course difficulty, and paid employment: Comparison between Western Australia and United Kingdom'. Physiotherapy Theory and Practice, 22 (6), 317-328 https://doi.org/10.1080/09593980601059550

Vahey, D.C., Aiken, L.H., Sloane, D.M., Clarke, S.P., and Vargas, D. (2004) 'Nurse burnout and patient satisfaction'. Medical Care, 42, II57-II66 https://doi.org/10.1097/01.mlr.0000109126.50398.5a

Whiteside, D., Stubbs, B., and Soundy, A. (2014) 'Physiotherapy students' experiences of bullying on clinical internships: A qualitative study'. Physiotherapy, 100 (1), 41-46 https://doi.org/10.1016/j.physio.2013.06.005

Yerkes, R.M. and Dodson, J.D. (1908) 'The relation of strength of stimulus to rapidity of habitformation'. Journal of Comparative Neurology, 18, 459-482 https://doi.org/10.1002/cne.920180503

Ying, Y.-W. (2008) 'Variation in personal competence and mental health between entering and graduating MSW students: The contribution of mindfulness'. Journal of Religion \& Spirituality in Social Work: Social Thought, 27 (4), 405-422 


\section{Appendix 1}

\section{Pre-placement focus group}

(1) Could you identify any potential sources on placement that may give rise to you feeling pressurized?

(2) Can you tell us how you deal with them if they do occur?

(3) Do you feel that there are times when you possibly feel you may not meet the needs of your patients?

(4) If there are, how do you normally deal with these if they occur?

(5) In your opinion are some clinical placements more demanding than others?

(6) If this is the case why do you imagine that this may be the case?

(7) Do the journeys you undertake travelling to and from your placements sometimes constitute a pressure?

(8) If they do sometimes, how do you cope with them?

(9) What suggestions do you have for looking after yourself physically and mentally whilst you are on placement?

(10) Are there any possible occasions on your placement which you feel compromise your performance?

\section{Post Placement focus group}

(1) Have you been able to maintain the practice of mindfulness whilst you have been on your placement?

(2) If you have not, what has prevented you doing it?

(3) If you have not been able to do it $\times 3$ a week, how long have you been able to practise it?

(4) Apart from doing $\times 3$ a week in your own time, have you been able to do it during the time you are on placement?

(5) Could you tell us if the practice of mindfulness has had any impact on your placement experience?

(6) Are there any situations that have been especially helped by your practice of mindfulness?

(7) Are you aware of the impact of the practice of mindfulness on your performance during your placement experience?

(8) Have there been any other effects of practicing mindfulness than on your placement experience?

(9) Would you consider using mindfulness in the future? 